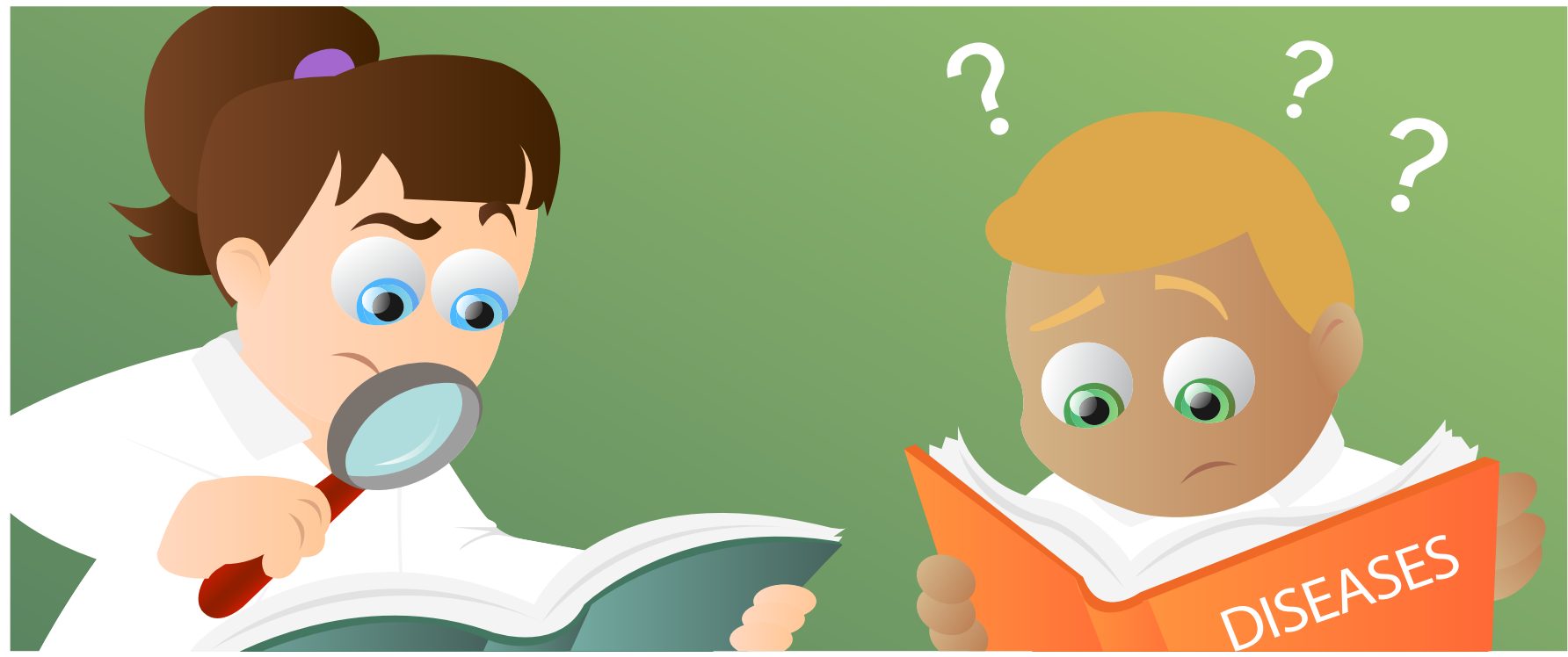

\title{
WHY STUDYING RARE DISEASES IS SO IMPORTANT: DO YOU KNOW OF THIS DISEASE?
}

\section{Federica Lupoli* and Annalisa Pastore ${ }^{2}$}

${ }^{1}$ Department of Biotechnology, Chemistry and Pharmacy, University of Siena, Siena, Italy, ²Maurice Wohl Institute, King's College London, London, UK

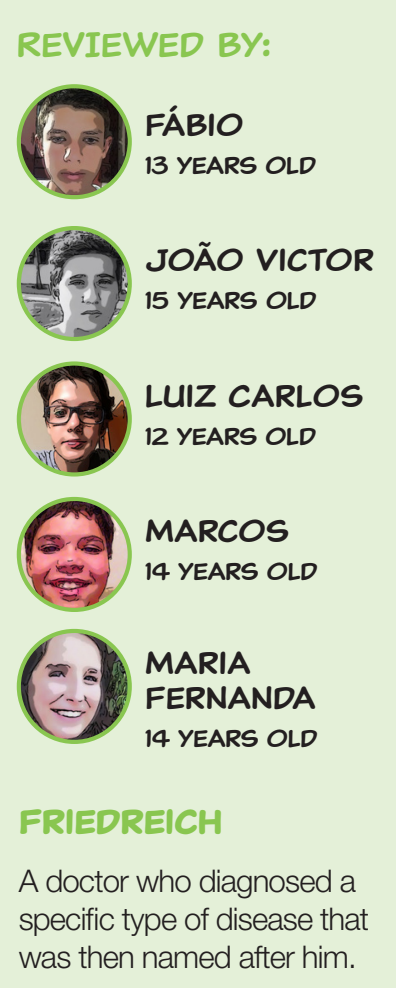

Some diseases affect many people and are of course very bad. Some other diseases affect just a few people and are called rare diseases. This sounds like a good thing but... if you are one of the few people affected by a rare disease, this is not a good thing! It is actually very bad because, often, pharmaceutical companies are not interested in developing a treatment for you because too few people would buy the drugs. In this article, Federica will tell you about her experience with a rare disease and explain what causes it and what can be done, if anything, to cure this very nasty disease. We hope that you can help us to find a cure.

\section{INTRODUCTION}

My name is Federica. I have a disease with a difficult name: Friedreich's ataxia [1]. For simplicity, we will abbreviate this name to FRDA. Ataxia means the loss of full control of body movement. It affects balance, coordination, and speech. There are different forms of ataxia. The form of ataxia that I have was named after Nikolaus Friedreich, a German medical doctor, who was the first to diagnose the disease between 1863 and 1877 in five patients 
ATAXIA

A disease associated to loss of the ability to move.

GENE

The place where the instructions to build our bodies are kept. who were initially believed to have other diseases that have similar (but not identical) symptoms [2].

\section{WHAT IS FRDA?}

First, let me reassure you: FRDA is not an infectious disease, meaning that you cannot catch it from another person like you can catch the flu or measles. FRDA is a disease that I have inherited from my parents and that I could transmit to my children. What I mean is the following: as you may know, a baby inherits half of its genetic information (on whether it will have blue or brown eyes, blonde or brown hair, how intelligent it will be, etc.) from the mother and half from the father. This information is called genetic because it is stored in some tiny entities called genes. Each gene contains the instructions to produce a specific protein. Proteins are what make us functional, living creatures, and each protein has a role in the cell. The genes are contained in structures called chromosomes. All human cells have 23 pairs of chromosomes ( 1 of each pair from mummy and 1 from daddy).

The reason why we inherit one set of chromosomes each of our parents is to make sure that we are all unique individuals. In other words, this process ensures that we take some characteristics (such as hair or eye color) from our mother and some from our father. It is important that each of the parents transmits only half of the genetic information because the union of these two halves makes one individual. Otherwise the body would get confused. What happens when the chromosomes from mom and dad contain different information? How does the body decide which information to use? For example, will the baby have blue eyes like mom or brown eyes like dad, or will he have brown or blonde hair? In most cases, one characteristic is less strong than the other and is called recessive. The term recessive means that the characteristic can be "carried" by an individual without actually showing up in the individual's body. In this case, the individual is called a "carrier." Only when an individual has two copies of that recessive characteristic will it appear.

But the information in the genes is not just about the eye or the hair color. Some genes control critical functions of the body. If these critical genes happen to have small mistakes in them (called mutations), they might contribute to disease because important bodily functions might not happen properly. If these mutated genes are recessive, the child will not have the disease and would not show any symptoms if the mutant gene is received only from one parent, but the child will develop the disease if, and only if, he/she gets a copy of the mutant gene from both parents. In other words, as the figure shows, the parents, both carriers, have one chance out of four of passing the two mutant recessive genes to their child (Figure 1). The baby that gets two mutant genes from the parents will, sadly, develop the disease. 


\section{FIGURE 1}

How characteristics are transmitted from parents to children. Characteristics are transmitted by instructions in the genes. Each of the two parents provides half of the genes to each child. If the gene is very strong

("dominant"), it is enough to have one copy to have that characteristic. If the characteristic is recessive, the child needs to get two of the same genes, one from each parent, to show the characteristic. This means that a child has one chance out of four to obtain a specific recessive characteristic (for instance, eye color, shape of the nose, and a genetic disease) if only one of the two parents has it.

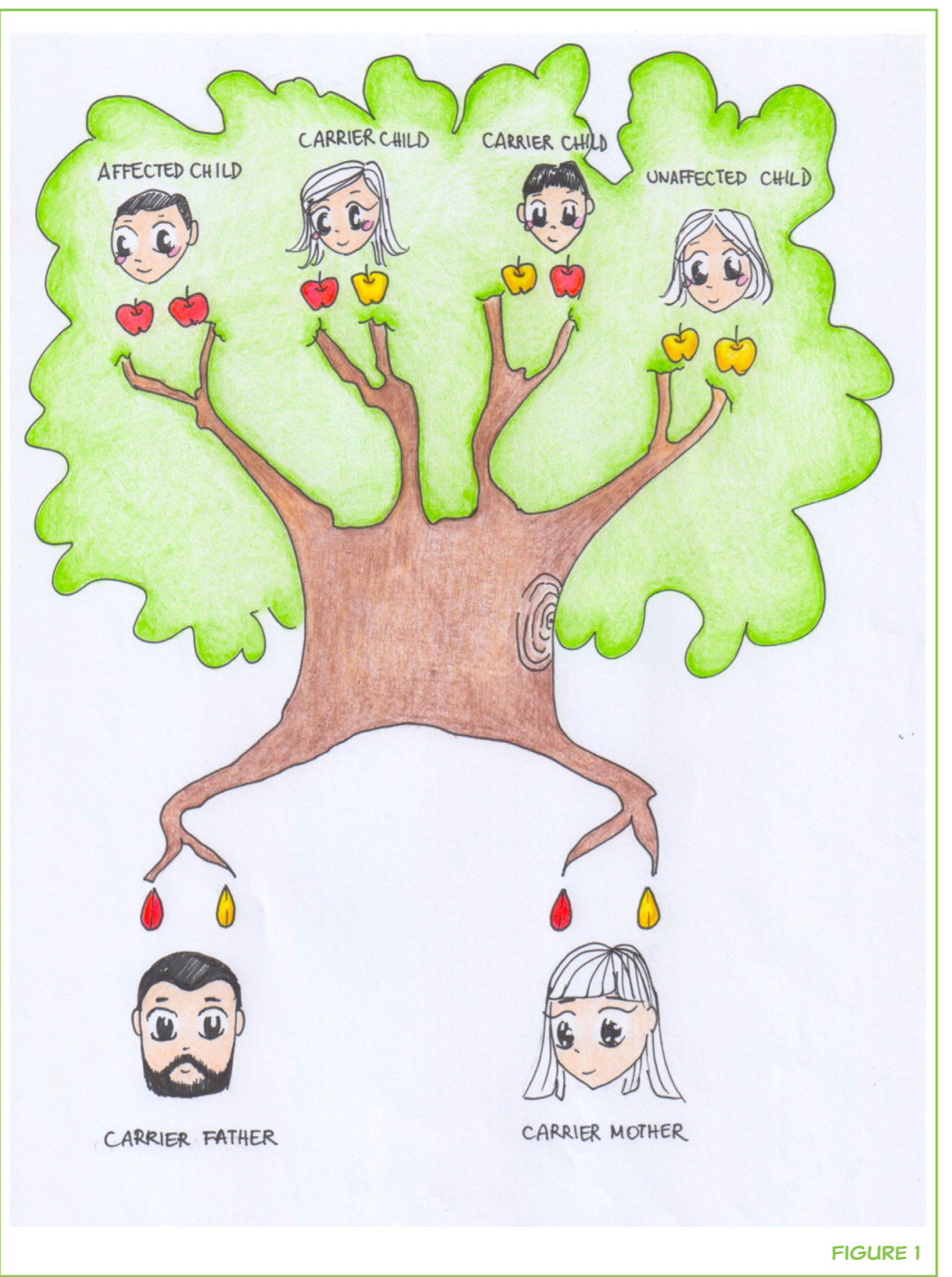

FRDA is a recessive disease and is caused by a mutation in one part of a specific gene named FXN. This gene was finally identified as the cause of FRDA in 1996, after a long hunt [3]. Unfortunately, my parents were both carriers of the mutated FXN gene, and both gave me the mutated copy. FRDA affects 1-2 people in every 50,000, making it the most common of the inherited ataxias $[4,5]$. FRDA is classified as a rare disease because there are many other diseases like cancer or diabetes that are much more common. However, if you think that this incidence is rare, please estimate how many cases there will be, say, in London, New York, or Mexico City, which have several millions of inhabitants. In any case, you will probably 


\section{NEURODEGENE- RATION \\ Disease that is associated with breakdown and malfunctioning of the nervous system which becomes progressively worse in time.}

\section{FIGURE 2}

A typical FRDA patient in a wheelchair. People with FRDA first appear healthy, but over time, they lose the ability to walk. Their feelings, thoughts, wishes, and aspirations remain the same, but they develop inhabilities.

understand that to me it does not matter that FRDA is less "important" than other diseases: FRDA happened to me.

\section{WHAT ARE THE SYMPTOMS?}

FRDA is what is called a neurodegenerative disease because it is associated to neurodegeneration. The first part of this word, neuro, refers to the nervous system, while the last part, degenerative, means that the symptoms continue to get worse. What are the symptoms? Although the causes are mostly in the nervous system, the symptoms hit other organs, including the muscles with in the heart. The typical symptoms are instability and awkwardness while walking and clumsiness. Twisting of the spine (scoliosis) is often already present when the other symptoms appear. In rarer cases, an enlargement of the heart appears before the clumsiness starts. As the disease progresses, the muscles of the body become weaker, and most of the people affected by this disease end up in wheelchairs (Figure 2). Because of the loss of coordination that occurs

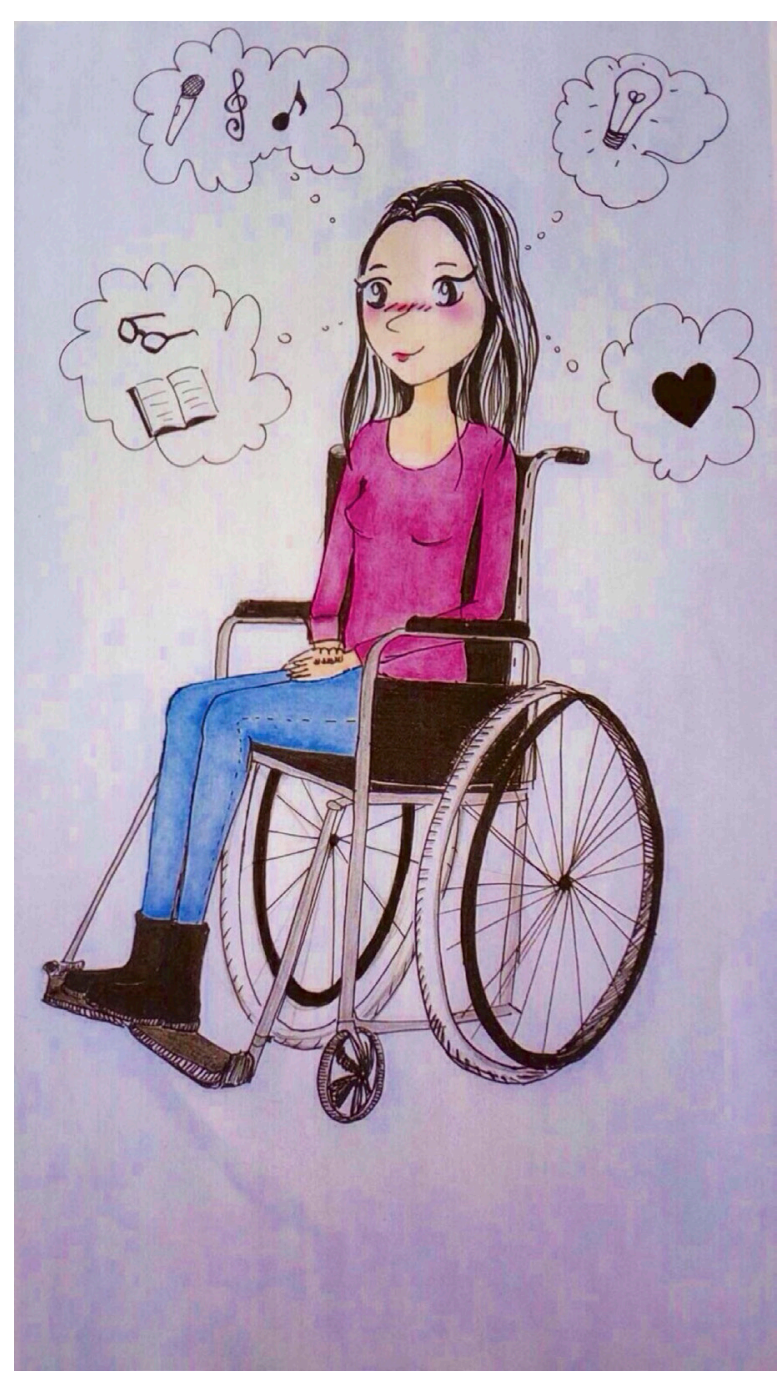


in FRDA, even the simplest activities such as speaking, eating, brushing the teeth, combing the hair, and writing become difficult. Some organs are more heavily affected than others. The sensory system is unaffected, meaning that people with FRDA still feel touch, pain, cold, and heat but with a delay. What I mean is that, since the nervous system is affected by the disease, the speed at which nerve signals travel is altered. It can take people with FRDA half a second longer to feel pain, but the intensity of the pain is the same.

The age at which the symptoms first appear (and their severity) can vary from individual to individual, but symptoms typically first appear during the teenage years. In my case, I was only 9 when the first symptom, a cardiac problem, appeared. When I was 13, I started having problems walking, but I did not yet have a diagnosis. The diagnosis came only later, thanks to a genetic test. You can see how important is to have these genetic tests, but such tests can be done only when we know which gene is involved. This is not always the case, and I am very thankful to those researchers who found the FXN gene.

Even when I was finally diagnosed, the only thing I knew was the name of my disease: Friedreich's ataxia. At the time, I did not have easy access to the Internet because it was not as widely used as it is now. All I knew was that "iron was accumulating in my cells," which was actually true. I was curious about everything and wanted to know more. I started asking my parents a lot of questions, questions that they were unable (or most likely pretended to be unable) to answer. I started to do my own research and to investigate the causes of FRDA to understand its causes rather than its symptoms. To me, the causes were much more interesting than the symptoms: I could directly experience them myself. Knowing the causes was, instead, my first step toward facing the problem.

\section{WHAT CAUSES FRDA?}

What happens when we have a mutation in the FXN gene? It might seem strange, but it is all caused by too little of a specific protein. Let me clarify what I am talking about. The meat (therefore, our muscles too) that we eat, eggs, and many other foods are rich in proteins. But proteins are not all the same: there are many different ones. In the human body, we have between 20,000 and 25,000 different proteins. Each of them is like a "worker" and has its own specific job or function within a society, the "cellular society". In all societies, workers perform at least one function and are in general very important for the well-being of several others, if not everybody. FRDA patients, who carry a mutated FXN gene, have a deficiency of only one of these proteins or "workers," a protein that is called frataxin. Frataxin is produced, but not enough of it. For this deficiency to have such a profound effect, frataxin must be a very important worker even though, before the FXN gene was found, nobody had ever noticed it! This of course leads us to ask: what exactly is the function of 
IRON-SULFUR CLUSTERS

Small molecules made of iron and sulfur. They can have different geometries, some are rectangular, others like small cubes, and others more complex.

frataxin? This topic is still hotly debated, meaning that nobody really knows for sure.

It has taken us 20 years and though we are still only at the beginning of a long tunnel we do now know a few facts about frataxin. First, frataxin is present in all cells of the body. The highest levels are found in the heart and spinal cord, while lower levels are present in the brain, liver, muscles, and pancreas. Frataxin is a protein involved in at least one cellular process. This process has to do with getting us energy. Without it, we would die. One of the "fuels" we use in the process of getting energy are molecules called "iron-sulfur clusters" that are literally clusters of iron and sulfur that are arranged in different geometric patterns. These iron-sulfur clusters work as switches, meaning they can be in two different states, like a light switch, and going from one state to the other produces energy. Iron-sulfur clusters are usually attached to proteins, which carry them around and use them when needed. Iron and sulfur are very important elements but, at the same time, are very toxic. By attaching iron-sulfur clusters to proteins, our bodies have found a clever way to store these elements and use them to release energy when needed. But these clusters do not pre-exist and are not produced for free. To produce them, we need specialized machines in our bodies, which are made of several different proteins, much like an assembly line [6]. Frataxin seems to be an important part of this assembly line [7, 8]. Frataxin seems to be the traffic light that says "now we need new clusters" or "now we have too many clusters, stop the production" (Figure 3). This role of frataxin is crucial because if too many iron-sulfur clusters are produced, then iron and sulfur form toxic deposits that can damage the cells they build up in. This is what happens in FRDA patients.

\section{IS THERE A CURE?}

You might ask why there is no cure for FRDA. I wish there was one. Treatments such as physiotherapy are strongly advised for FRDA patients, since these treatments help to slow down the progression of the disease. But physiotherapy only treats the disease, it does not cure it. It should be possible to find some other molecule that carries out the work of frataxin; if this alternative could be found, doctors could give doses of it to FRDA patients or maybe doctors could find ways to convince the body to produce more frataxin. These routes are now being attempted, but it is hard because proteins cannot be introduced easily from outside the body. Our body is usually quite suspicious of things introduced from the outside and destroys most of them or chops them up so that their components can be recycled to produce new proteins. Also, it is not easy to reprogram the machine responsible for the low production of frataxin in FDRA patients.

Now, you know everything about this rare and for most people unknown disease. But you might be still wondering: does FRDA affects mental ability? Not 


\section{FIGURE 3}

Cartoon to explain the role of frataxin in the cell.

Frataxin acts as a red light that tells the cell when to produce the iron-sulfer clusters.

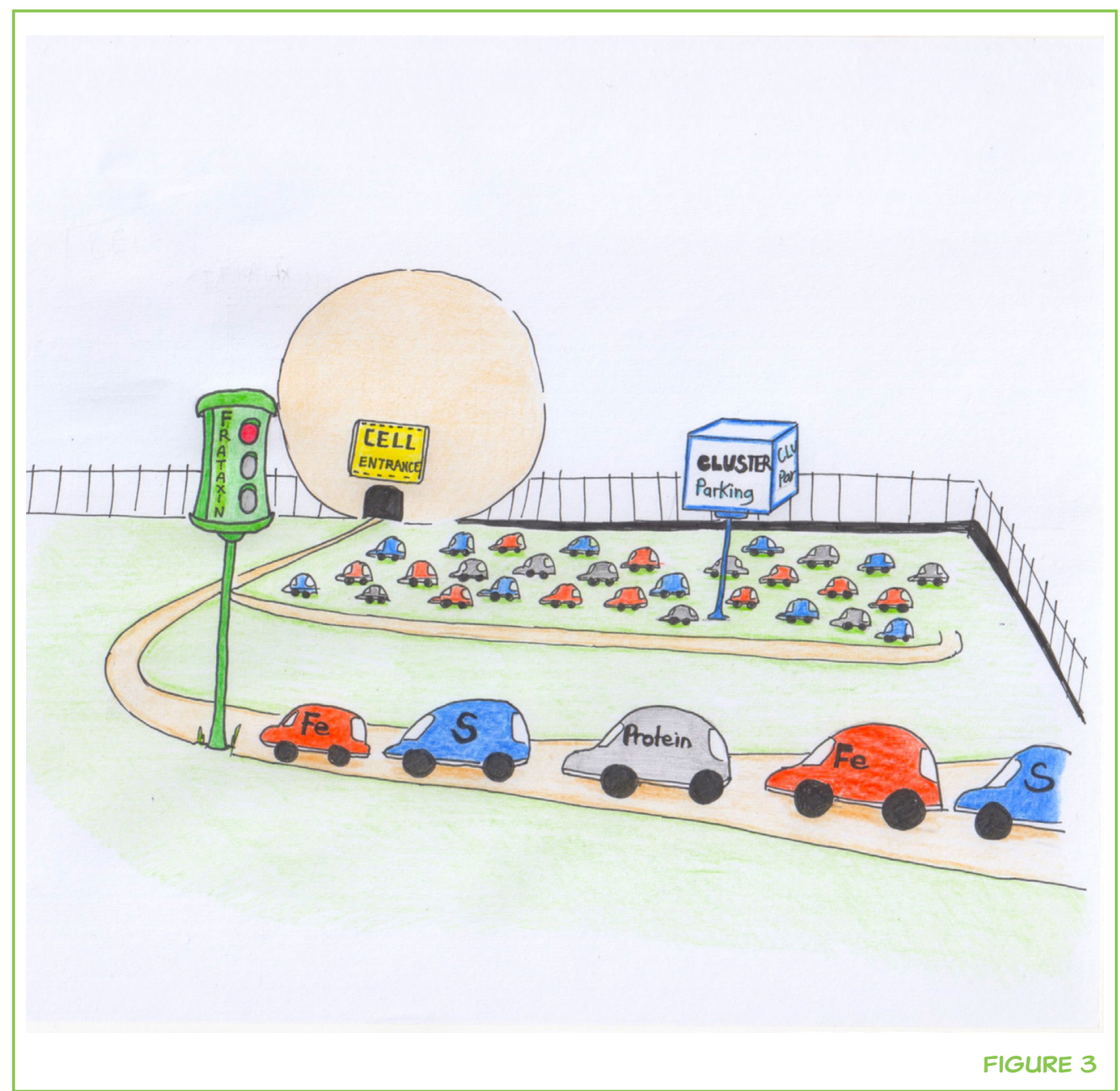

in the least! Only the body changes. The mind, the intelligence, the interests, the hobbies, and the passions are still the same. In fact, now I am 22 years old, and my dream is still the same as when I was a child: knowing why things happen, focusing on one thing in particular: Friedreich's ataxia.

\section{ACKNOWLEDGMENTS}

The authors wish to thank Chiara Paterno for drawing the figures and Neri Niccolai for supervision of FL during her Master thesis and moral support. Some of the research described in this review from the AP group was funded by MRC.

\section{REFERENCES}

1. Pastore, A., and Puccio, H. 2013. Frataxin: a protein in search for a function. J. Neurochem. 126:43-52. doi:10.1111/jnc.12220

2. Friedreich, N. 1863. Ueber degenerative Atrophie der spinalen Hinterstränge [About degenerative atrophy of the spinal posterior column]. Arch. Pathol. Anat. Phys. Klin. Med. 26:391-419. 
3. Campuzano, V., Montermini, L., Moltó, M. D., Pianese, L., Cossée, M., Cavalcanti, F., et al. 1996. Friedreich ataxia: autosomal recessive disease caused by an intronic GAA triplet repeat expansion. Science 271:1423-7. doi:10.1126/ science.271.5254.1423

4. Pandolfo, M., and Pastore, A. 2008. The pathogenesis of Friedreich ataxia and the structure and function of frataxin. J. Neurol. 256(Suppl 1):9-17. doi:10.1007/ s00415-009-1003-2

5. Chiang, S., Kovacevic, Z., Sahni, S., Lane, D. J., Merlot A. M., Kalinowski, D. S., et al. 2016. Frataxin and the molecular mechanism of mitochondrial iron-loading in Friedreich's ataxia. Clin. Sci. (Lond.) 130:853-70. doi:10.1042/CS20160072

6. Maio, N., and Rouault, T. A. 2015. Iron-sulfur cluster biogenesis in mammalian cells: New insights into the molecular mechanisms of cluster delivery. Biochim. Biophys. Acta. 1853:1493-512. doi:10.1016/j.bbamcr.2014.09.009

7. Adinolfi, S., lannuzzi, C., Prischi, F., Pastore, C., lametti, S., Martin, S. R., et al. 2009. Bacterial frataxin CyaY is the gatekeeper of iron-sulfur cluster formation catalyzed by IscS. Nat. Struct. Mol. Biol. 16:390-6. doi:10.1038/nsmb.1579

8. Prischi, F., Konarev, P. V., lannuzzi, C., Pastore, C., Adinolfi, S., Martin, S. R., et al. 2010. Structural bases for the interaction of frataxin with the central components of iron-sulfur cluster assembly. Nat. Commun. 1:95. doi:10.1038/ncomms1097

SUBMITTED: 23 November 2016; ACCEPTED: 13 February 2017;

PUBLISHED ONLINE: 09 March 2017.

EDITED BY: Sabine Kastner, Princeton University, USA

CITATION: Lupoli F and Pastore A (2017) Why Studying Rare Diseases is So Important: Do You Know of This Disease? Front. Young Minds 5:3. doi:10.3389/frym.2017.00003

CONFLICT OF INTEREST STATEMENT: The authors declare that the research was conducted in the absence of any commercial or financial relationships that could be construed as a potential conflict of interest.

COPYRIGHT ( 2017 Lupoli and Pastore. This is an open-access article distributed under the terms of the Creative Commons Attribution License (CC BY). The use, distribution and reproduction in other forums is permitted, provided the original author(s) or licensor are credited and that the original publication in this journal is cited, in accordance with accepted academic practice. No use, distribution or reproduction is permitted which does not comply with these terms.

\section{REVIEWED BY}

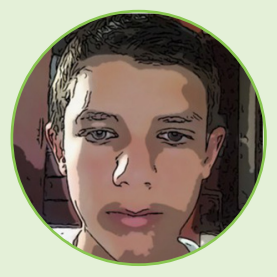

\section{FÁBIO, 13 YEARS OLD}

Hil I am in the eighth grade at Equilibro School. My favorite subjects in school are math, science, and history. I like to play tennis, build robots, and develop software for computers. I also spend some of my free time watching YouTube and playing computer games. 


\section{JOÃO VICTOR, 15 YEARS OLD}

Hello! I am 15 years old and am in the ninth grade. I was born in Jaboticabal, Brazil, and still live there. I like studying, reading books, and playing videogames. My favorite hobby is soccer.

\section{LUIZ CARLOS, 12 YEARS OLD}

My name is Luiz Carlos. I am 12 years old and a sixth grade student at Equilíbrio School. I really enjoy studying math, science, Spanish, and English. My favorite hobbies are soccer, videogames, and skateboarding. I also like long walks with my friends and family.

\section{MARCOS, 14 YEARS OLD}

$\mathrm{Hi}$, my name is Marcos, and I am 14 years old. I live in Jabotical, Brazil, and go to Equilibrium School. I love my school and I am in the ninth grade. I enjoy sports and play soccer and swim. Some of my hobbies include cooking and hanging out with my friends.

\section{MARIA FERNANDA, 14 YEARS OLD}

Hi! My name is Maria Fernanda, and I am 14 years old. I live in Jaboticabal, Brazil, and I am in the ninth grade at Equilibrio School. I have dear parents, two brothers, and a dog. I would like to become a physician. I am very sociable, and I love dancing jazz, listening to music, and hanging out with my friends.

\section{AUTHORS}

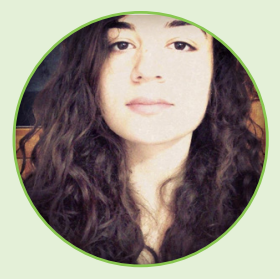

\section{FEDERICA LUPOLI}

I am a postgraduate student. I have studied chemistry and I am particularly interested in biochemistry. My dream is to study proteins, one in particular: Frataxin. I have heard this name since I was 11 because I was told that I did not have enough, but I started to understand what this protein does only a few years ago, when I started to work on my undergraduate dissertation. My short-term goal is to do a PhD, which can enable me to understand more about this protein and allows me to undertake a career as a researcher. I am still young, and the world of research is so new to me, charming; I do not have experience in it, and I am just a beginner. I feel like an explorer who is discovering an unknown yet fascinating land. *federica1204@icloud.com

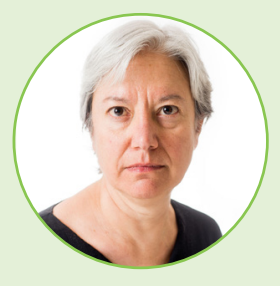

\section{ANNALISA PASTORE}

I studied chemistry and travelled all over the world to do my work. My job is to discover the shape of proteins because the way proteins are assembled in the space determines what they do in the human body. I love my work. Twenty years ago, by chance, I started working on a particular protein, frataxin, because it was responsible for a disease. Twenty years later, I am still working on it and find it always more interesting. My dream is to understand what the function of frataxin is and why it is so important that, if we do not have enough, we become ill. *Annalisa.Pastore@crick.ac.uk 